\title{
Magnetic Alignment Detection Using Existing Charging Facility in Wireless EV Chargers
}

\author{
Yabiao Gao, ${ }^{1}$ Aleff Antonio Oliveira, ${ }^{1,2}$ Kathleen Blair Farley, ${ }^{3}$ and Zion Tsz Ho Tse ${ }^{1}$ \\ ${ }^{1}$ College of Engineering, The University of Georgia, Athens, GA 30602, USA \\ ${ }^{2}$ Gama College of Engineering, University of Brasilia, 72.444-240 Gama, DF, Brazil \\ ${ }^{3}$ Southern Company Services, Inc., Birmingham, AL 35291, USA \\ Correspondence should be addressed to Zion Tsz Ho Tse; ziontse@uga.edu
}

Received 31 July 2015; Accepted 2 December 2015

Academic Editor: Pietro Siciliano

Copyright (C) 2016 Yabiao Gao et al. This is an open access article distributed under the Creative Commons Attribution License, which permits unrestricted use, distribution, and reproduction in any medium, provided the original work is properly cited.

\begin{abstract}
Wireless charging is a promising outlet to promote the electric vehicle (EV) industry due to its safe and noncontact manner. Wireless $\mathrm{EV}$ chargers require the secondary receiver coil to be well aligned with the primary station for efficient charging, which could require more of the driver's time and attention when parking a vehicle. Therefore, this paper presents a magnetic alignment system to assist the EV driver during parking. The magnetic alignment approach uses the existing coil and frequency tracking control electronics of wireless chargers to detect the distance between the two coils while using 4 small auxiliary coils for direction and fine adjustment, leading to a cost effective detection method for coil alignment in electric vehicle wireless charging (EVWC). The testing results of a prototype show acceptable measurement correctness and the mean error for ten trials in range detection is within $0.25 \mathrm{~cm}$ at three different misalignment conditions $(10.5,15$, and $20 \mathrm{~cm})$. The positioning accuracy of coil alignment is within $1.2 \mathrm{~cm}$ for three different start positions with the auxiliary coils.
\end{abstract}

\section{Introduction}

Over the past decade, pure electric vehicles (EVs) and plug-in hybrid electric vehicles (PHEVs) have increased in popularity due to environmental awareness and fossil fuel price fluctuations [1-7]. Wireless charging is a competitive option to overcome the inconvenience of plug-in EV charging and the relatively low energy density stored in batteries by opportunity charging [2]. A wireless EV charger typically includes power electronics that convert the grid power to a high frequency power source: the primary coils placed/buried on ground, the secondary coil mounted underneath the chassis of the EVs, on-board electronics that rectify the secondary output to charge the EV battery, and a communication module between ground facility and the on-board electronics [8].

The efficiency of wireless charging highly relies on the alignment condition between the two charging pads [9]. The wireless $\mathrm{EV}$ chargers can commonly tolerate a misalignment error of only $10 \mathrm{~cm}$, which presents a challenge to EV drivers while parking over a wireless charging station [10].
Birrell et al. investigated the effects of drivers' behavior and parking alignment on wireless chargers [10]. According to their study, the mean longitudinal misalignment is more than $70 \mathrm{~cm}$ when the drivers parked over a wireless charging pad with no guidance from external support. The study also shows that only $5 \%$ of EVs can park well enough to achieve efficient wireless charging. Since the wireless chargers can only endure limited misalignment, advanced frequency control methods and coupler design have been investigated with the goal to improve the alignment flexibility for EV wireless charging. These advanced design indeed have better performance than a common one. However, it still cannot compensate for parking errors greater than $0.7 \mathrm{~m}$ (which is greater than the diameter of the coils). Hence, a vehicle alignment system should be a necessary subsystem of wireless EV chargers. Additionally, the alignment system has been seen as an essential module of wireless EV chargers in the newly released SAE technical standards (SAE-J2954) [11].

To the best of the authors' knowledge, the magnetic method is the best option for alignment detection. It uses 


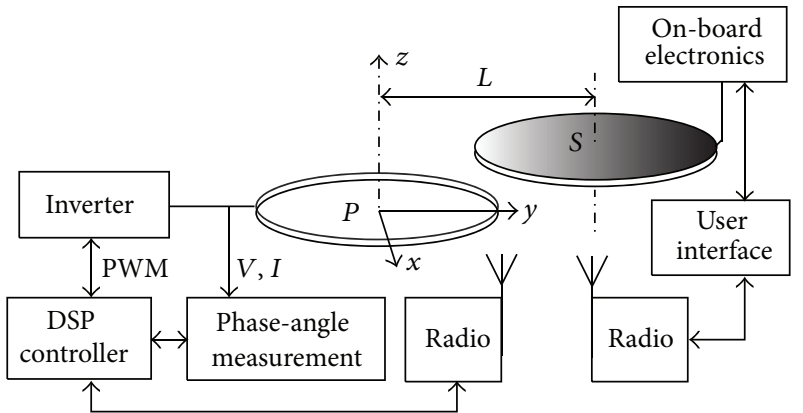

(a)

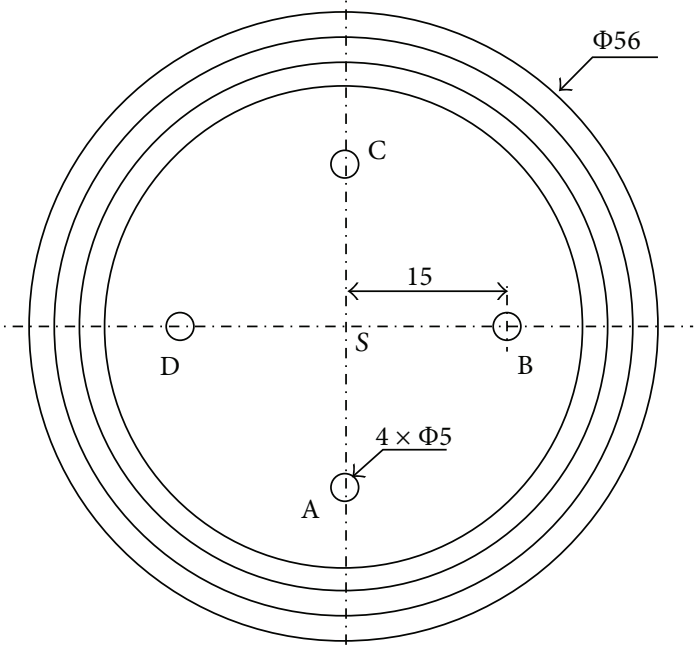

(b)

FIGURE 1: (a) Block diagram of the proposed magnetic alignment system using existing wireless charging equipment; (b) secondary coil with four small auxiliary coils (A-D) for direction and fine adjustment (unit: $\mathrm{cm}$ ). $P$ is the primary center while $S$ is the secondary center.

the existing coil to generate a weak magnetic field that is detected by magnetic sensors installed on the secondary side. Although RF positioning can meet the accuracy requirement of alignment control, more than one RF antenna need to be fixed on the primary side, which potentially increases its cost and leads to a complex system. Other potential detection methods include RFID positioning, GPS, optical detection, mechanical stop, and mechanical arm. The accuracy of RFID is more than $50 \mathrm{~cm}$ which is inaccurate for alignment. The cost becomes increasingly high if the pressure sensors are buried underground. Machine vision seems promising in vehicle alignment. However, it cannot work if the charging stations are covered with snow in winter. The GPS signals are unavailable sometimes, and the positioning accuracy is limited to $5 \mathrm{~m}$ [12]. The mechanical stop is large in size and cannot support automated alignment control, while using a mechanical arm will increase the cost and make the system more complex.

There is currently still limited literature available regarding the design of an alignment system for wireless EV chargers. Ni et al. presented a conceptual radio alignment system for EV wireless charging [13]. The system applied eight radio nodes with four on the ground and the other four mounted underneath the secondary pad to sense the relative position between the primary and secondary coils. The radio nodes used by the system are based on an indoor ranging technique called wireless ad hoc system for positioning (WASP), which operates in 5.8-GHz ISM band with a bandwidth of $125 \mathrm{MHz}$ and achieves a distance measurement error of about $0.2 \mathrm{~m}$. Shuwei et al. introduced an alignment system using sixteen reference RFID tags and two readers placed on ground and one tracking tag attached to the vehicle [14]. Although the radio alignment method is an alternative option for $\mathrm{EV}$ wireless chargers, it can increase the system complexity and thus result in a high-cost wireless charging system. The price of each commercial radio reader can be as high as several thousand dollars, which surpasses the cost of the basic charging electronics. For example, the current price of a commercialized $3.3 \mathrm{~kW}$ plugless wireless $\mathrm{EV}$ charger is as low as $\$ 1260$ for Chevy Volt [15]. Therefore, the radio alignment system might encounter cost issues in an open market where the configuration that meets requirements with minimal cost survives. Moreover, the additional operating frequency band of the radio positioning system could possibly cause electromagnetic interference issues.

This paper introduces a magnetic sensing system for alignment in wireless EV chargers. The system utilizes the existing charging facility to generate a magnetic field and sense the relative distance between the two coil centers. The system also requires four minor coils to be installed on the secondary pad for direction detection using triangulation. The four small coils are also able to adjust the alignment when the two major coils are close enough, ensuring the primary and secondary pads are well aligned.

\section{Overview of Magnetic Alignment for Wireless EV Charging}

Figure 1(a) illustrates the components of the wireless charging system used for alignment detection. Since the phaseangle between output voltage and current of the inverter changes along with the operating frequency and coil spatial distribution, the distance between the primary and secondary coils can be measured by the phase-angle feedback and the WPT system's frequency characteristics on misalignment. The digital signal processor (DSP) controller switches the frequency of pulse width modulation (PWM) signals and acquires phase-angle signals and charging information from the vehicle side via wireless communication. Two halfbridge insulated gate bipolar transistor (IGBT) modules (FF100R12K4, Infineon) are employed to form the H-bridge 
that drives the transmitter coil to generate high frequency electromagnetic fields. The voltage/current induced in the receiver is rectified to DC to power the load or charge a battery. A National Instrument (NI) Data Acquisition (DAQ) card (NI CompactRio-9075) with wireless communication modules is used to transmit the data from the primary to the secondary side wirelessly. A user interface is developed in LabVIEW to display the alignment information for the driver while parking.

Figure 1(b) shows the mechanical schematic of the secondary coil. The four minor coils can detect its distance from the primary center when the two coils begin to overlap. Since the actual magnetic field strength and distribution are always different from the computational value, the minor coils' output distance is outputted by matching the immediate value with an experimentally acquired data space. This scenario is used when the two big coils are close enough with each other that the big-coil's detection limit might not be effective. The use of four coils allows the system to determine whether the driver needs to move left, right, forward, or backward. The zero misalignment occurs when the relative value of the four nodes is 0 . The four small coils are mounted symmetrically.

Figure 1 is the existing hardware for wireless charging except for the four minor coils and an ultrasonic sensor (MaxSonar-EZ2, MaxBotix Inc., Brainerd, MN, USA) for height measurement. Therefore, the alignment system shares most of the electronic components with the charging facility, leading to a low-cost detection. After completion of alignment operation, the DSP controller will tune its optimal switching frequency based on the phase-angle feedback as well as the battery's state of charge and then start charging.

Figure 2 is a block diagram of the phase-angle measurement module. The four relays are used to isolate the power electronics from the control electronics due to the high power in wireless charging. The comparators are used to transform the output voltage $\left(V_{s}\right)$ and current $\left(I_{s}\right)$ signals from the inverter into two square waveforms. The phase delay between $V_{s}$ and $I_{s}$ is measured by an exclusive-OR gate (XOR) that combines the two square waveforms to one pulse waveform. A low-pass filter converts the pulse into a DC signal $V_{\text {phs }}$; then the DSP reads the voltage signal and obtains the phase-angle information. The DC output of the filter is proportional to the phase-angle between $V_{s}$ and $I_{s}$. The DC input voltage is operated at a relatively low voltage (limited to $24 \mathrm{~V}$ ) during the vehicle alignment process, as lower voltage levels are much safer for the control electronics.

In the phase-angle measurement circuit, the voltage probe is directly connected to the output of the power inverter by a resistance divider. This is because the switching frequency is more than $10 \mathrm{kHz}$, and thus such high frequency makes a typical commercialized hall-effect voltage sensor unable to catch the fast response time. The AC current is measured by a current transformer. Although discrete Fourier transform (DFT) can be programmed in DSP for phaseangle measurements, using an XOR, and an RC filter greatly simplifies the embedded software development process and reduces the computational load of the DSP.

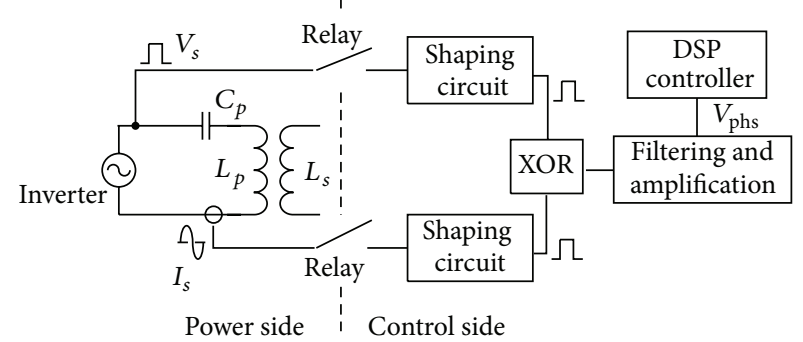

FIGURE 2: Phase-angle measurement between the inverter's output voltage and current.

\section{Range Detection Using Charging Coils}

Figure 3 shows the resonant tank using series parallel topology for wireless power transmission (WPT). The primary and secondary coil both have 12 turns. The inductance of primary coil $L_{p}$ is $65.3 \mu \mathrm{H}$ and the secondary coil inductance $L_{s}$ is $65.1 \mu \mathrm{H}$. The tuning capacitance for both sides $\left(C_{p}\right.$ and $\left.C_{s}\right)$ is $1 \mu \mathrm{F}$. According to the equivalent circuit shown in Figure 3(b), the circuit impedance $Z(\omega)$ is

$$
\begin{aligned}
Z(\omega)= & \frac{1}{j \omega C_{p}}+j \omega\left(L_{p}-L_{m}\right) \\
& +j \omega L_{m} / /\left(j \omega\left(L_{s}-L_{m}\right)+\frac{1}{j \omega C_{s}} / / R_{L}\right),
\end{aligned}
$$

where $j$ is the imaginary unit, $\omega$ is the angular frequency, $L_{m}$ is the mutual inductance between the two coils, and $R_{L}$ is the equivalent resistance of the battery, which can be calculated using the delivered power and voltage across the battery. For a desired $1.4 \mathrm{~kW} / 120 \mathrm{~V}$ battery charging condition, $R_{L}$ is $20 \Omega$.

The coupling coefficient $k$ is defined as

$$
k=\frac{L_{m}}{\sqrt{L_{p} L_{s}}} .
$$

According to the Neumann formula, the mutual inductance is a function of coil dimension and spatial arrangement. Since the coil dimension has been determined, the coupling coefficient is a function of misalignment and air gaps. Therefore, the coil misalignment can be measured through analyzing frequency characteristics of WPT.

Figure 4 is the simulated impedance and phase characteristics in the frequency domain with multiple coupling coefficient values. For each curve of the phase-angle in Figure 4(b), one zero-crossing point exists, which indicates the resonant frequency. The resonant frequency varies with different coupling coefficients. Thus, the lateral distance between two coils can be obtained through adjusting the frequency until the phase-angle becomes zero. The resonant frequency indicates the lateral distance.

For an accurate measurement, a calibration is necessary to build a data space that allows the resonant frequency to match with it. The built-in data space is composed of 25 sets of misalignments and resonant frequencies for each height. Since the vehicle chassis might be slightly varied due to 

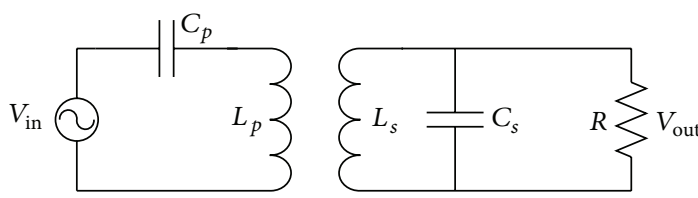

(a)

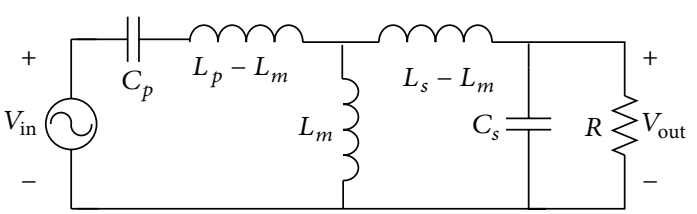

(b)

Figure 3: (a) Simplified circuit model of the WPT; (b) equivalent circuit.

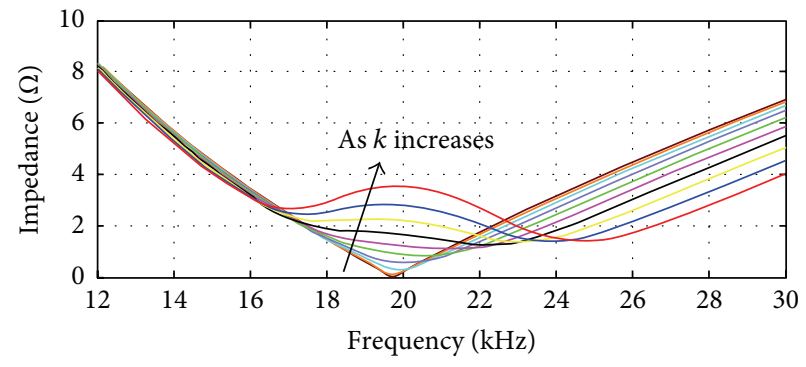

(a)

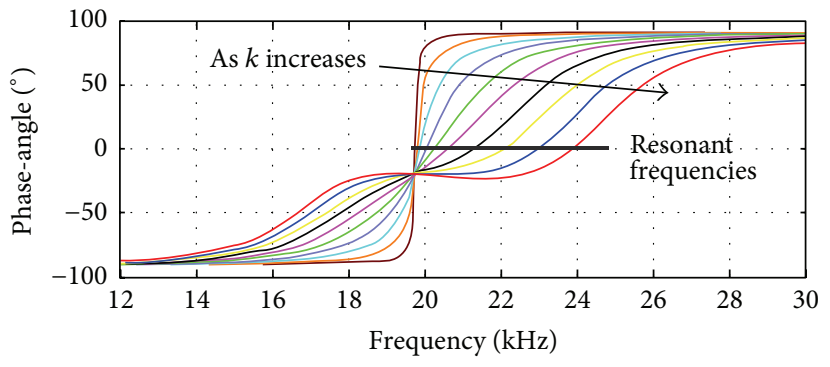

(b)

Figure 4: (a) Impedance magnitude across frequency domain; (b) phase-angle across frequency domain. The parameters of the wireless charging system were $L_{p}=65 \mu \mathrm{H}, L_{s}=65 \mu \mathrm{H}, C_{p}=1 \mu \mathrm{F}, C_{s}=1 \mu \mathrm{F}$, and $R=20 \Omega$, and the mutual inductance $L_{m}$ was assumed as 2.5, 5, 7.5, $10,12.5,15,17.5,20,22.5$, and $25 \mu \mathrm{H}$ in the simulation.

tire pressure or the weight it carries, the height should be taken into account when building the data space, making it a multidimensional array. The calibration is conducted for each step of $1 \mathrm{~cm}$ so the total calibrated ranging is up to $25 \mathrm{~cm}$ for each height. Following Figure 4(b), the misalignment value can be assumed to change linearly with the measured resonant frequency $f$ between two calibration points as close as possible. Hence, the misalignment $L$ can be obtained by

$$
L=L_{i}+\frac{f-f_{i}}{f_{i+1}-f_{i}}, \quad i \in[0, D)
$$

where $i$ is the index number of the calibrated lateral distance $L_{i}$ between two coil centers, $f_{i}$ and $f_{i+1}$ are the resonant frequency when the lateral distance is $L_{i}$ and $L_{i+1}$, and $D$ is the calibrated range and is 25 in our experiment.

Figure 5(a) shows the flowchart used for lateral detection. As shown in Figure 5(a), the resonant frequency is located through adjusting the frequency, reading the phase-angle feedback, and comparing between current and previous angles $\left(\theta_{\text {current }}\right.$ and $\left.\theta_{\text {previous }}\right)$. The resonant frequency is obtained when the current phase-angle $\left(\theta_{\text {current }}\right)$ is lower than $t$, which is close to zero. After that, the microcontroller will match the resonant frequency with the built-in data space and calculate the lateral distance by (3).

\section{Auxiliary Coils for Minor Adjustment}

The four minor coils act as an auxiliary device for minor adjustment to ensure the vehicle is parked perfectly. The
TABLE 1: Parameters of the auxiliary coil.

\begin{tabular}{lc}
\hline Specification & Auxiliary coil \\
\hline Inductance $(\mu \mathrm{H})$ & 17.1 \\
Resonant capacitor $(\mu \mathrm{F})$ & 3.7 \\
Number of turns & 10 \\
Diameter of coil $(\mathrm{mm})$ & 51.5 \\
Coil track width $(\mathrm{mm})$ & 1.0 \\
Coil track separation $(\mathrm{mm})$ & 1.0 \\
\hline
\end{tabular}

auxiliary coil inductance is measured by a LCR meter, and the resonant capacitor is calculated by

$$
C=\frac{1}{4 \pi^{2} f^{2} L},
$$

where $L$ is the inductance of the auxiliary coil and $f$ is the resonant frequency of the small coil. The switching frequency is assumed as $20 \mathrm{kHz}$ which is the proposed switching frequency of the wireless EV charger. Figure 6(a) shows the auxiliary coil was made in printed circuit board (PCB). Table 1 shows the auxiliary coil's specification.

Figure 6(b) shows the circuit diagram for the four auxiliary coils. It includes an inverting amplifier, a rectifier consisting of four Schottky diodes, and a film capacitor for filtering the output voltage variations. Since the operating frequency of the wireless charging system can range from $15 \mathrm{kHz}$ to $25 \mathrm{kHz}$, the electric components need to be able to operate in the frequency band. In Figure 5, the capacitor $\mathrm{C}_{0}$ together with the feedback resistor adds a null end to the Bode plot of the circuit, lowering the bandwidth of the amplifier and filtering high frequency noises. The rectifier and the filtering capacitor convert the alternating current (AC) 


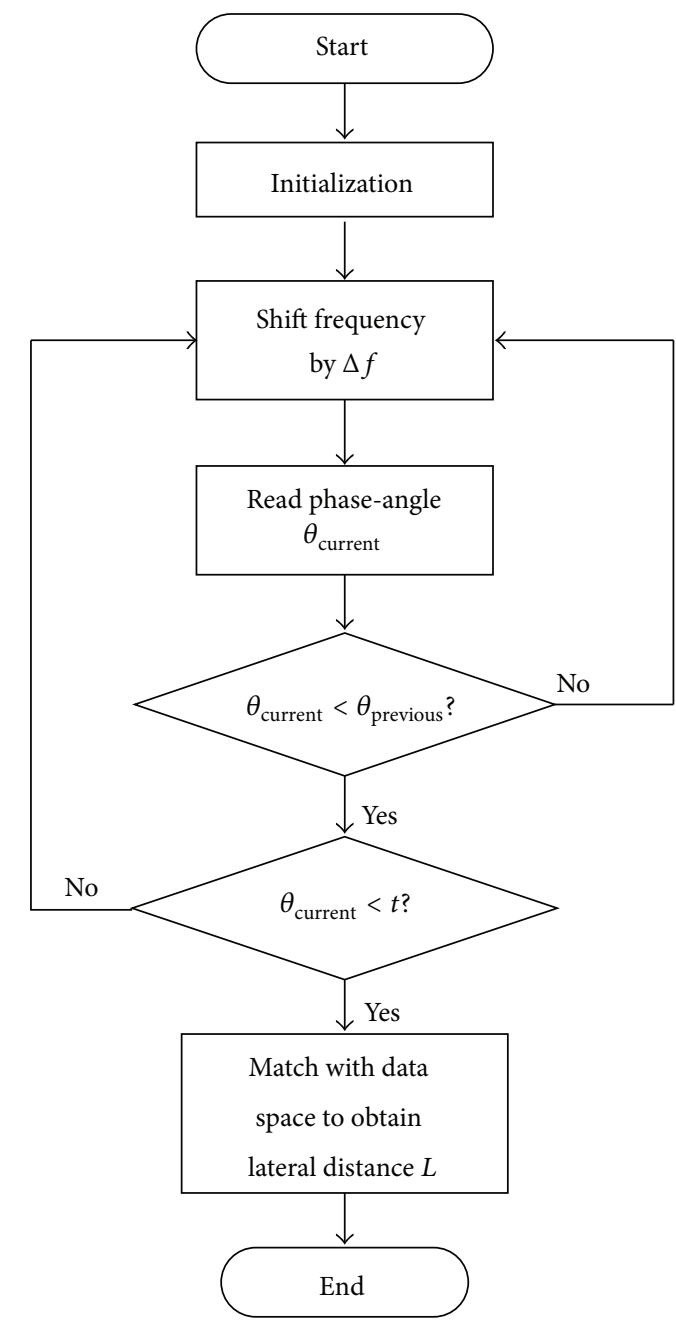

(a)

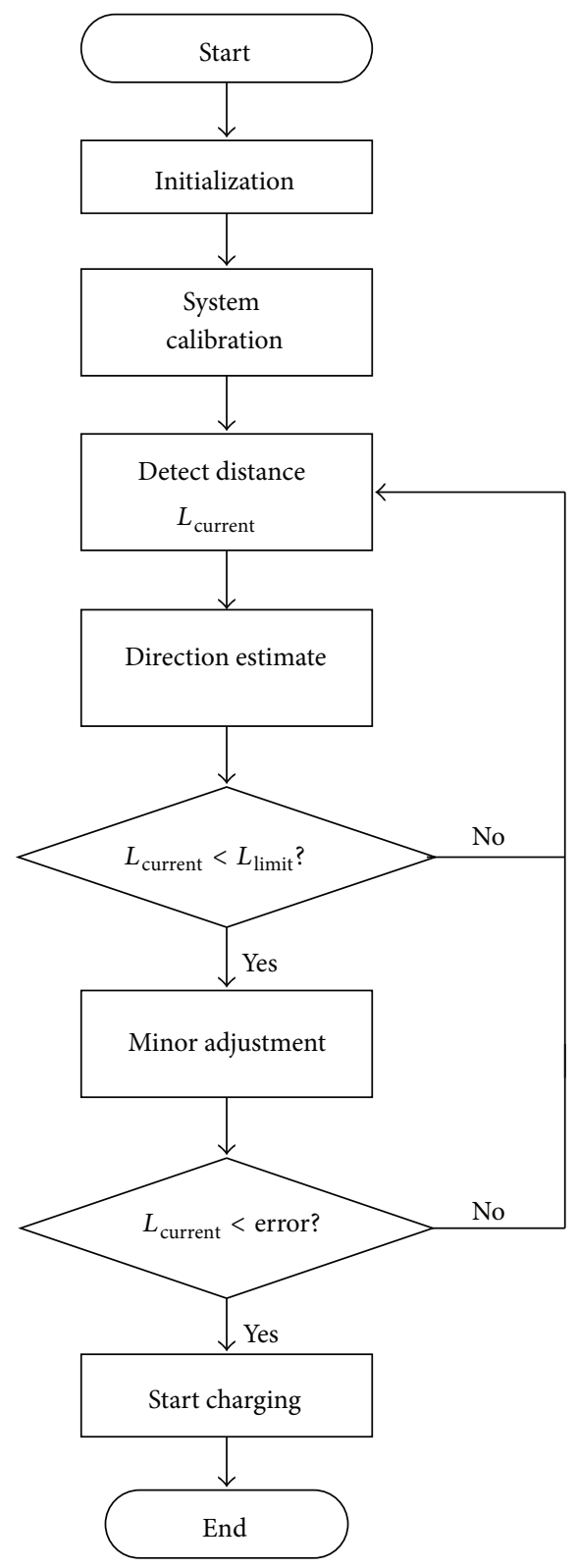

(b)

FIGURE 5: (a) Flowchart for lateral distance detection; (b) flowchart of operation planning of the magnetic alignment system.

signals of the amplifier to direct current (DC) signals which are then acquired by the NI DAQ module. Because the data card faces difficulty in acquiring the high frequency signal, it is necessary to convert the signal to DC first then the data card for further processing in LabVIEW.

4.1. Operating Plan of the Alignment System. The operation plan of the alignment detection is shown in Figure 5(b). When the vehicle is parked, the alignment system is automatically activated from sleep mode. Firstly, the charging facility reads the vehicle height and then calibrates and chooses the appropriate built-in data array for matching purposes. Secondly, it measures and displays the immediate lateral distance $L_{\text {current }}$ and the four auxiliary coils' outputs for direction estimation. Thirdly, it compares the current lateral distance with the previous one to decide whether it is the right time to alert the driver to start minor adjustments. Finally, the charging process is initiated after both the charging pads are well aligned and the driver shifts into park and locks the transmission.

\section{Results and Discussion}

5.1. Experimental Setup. Figure 7(a) shows the experimental platform used to validate the magnetic sensing for alignment 


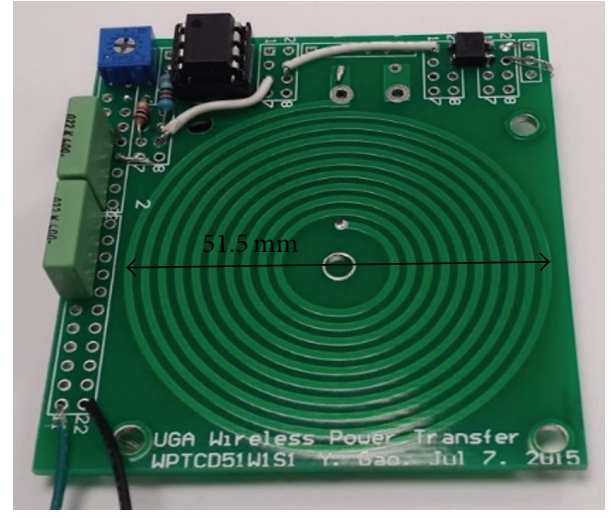

(a)

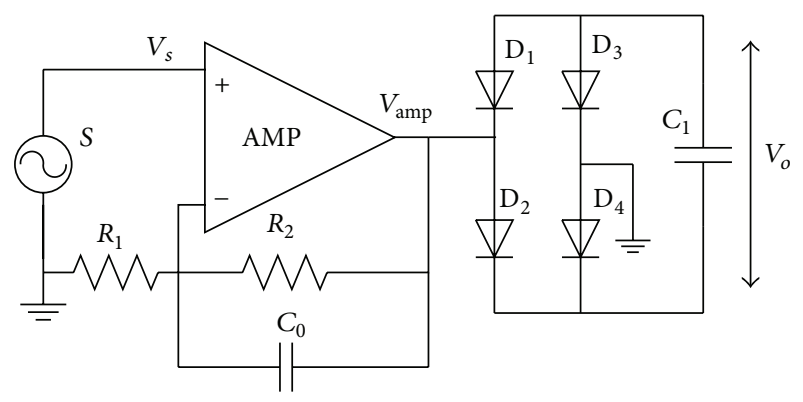

(b)

FIgURE 6: (a) A picture of auxiliary nodes; (b) circuit diagram for auxiliary coils.

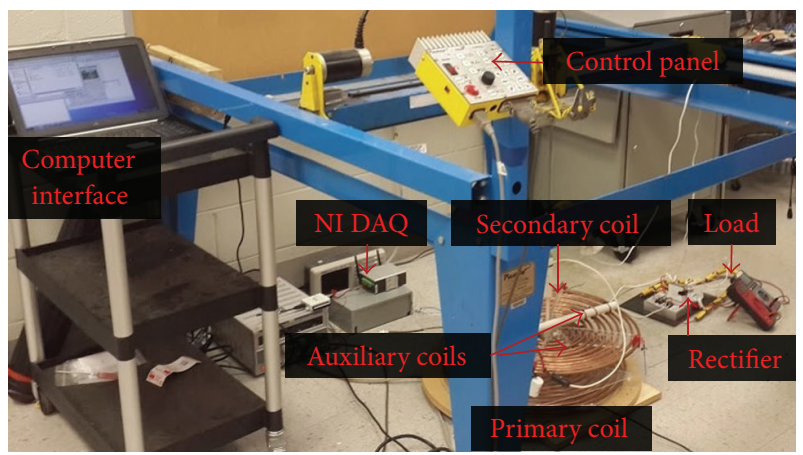

(a)

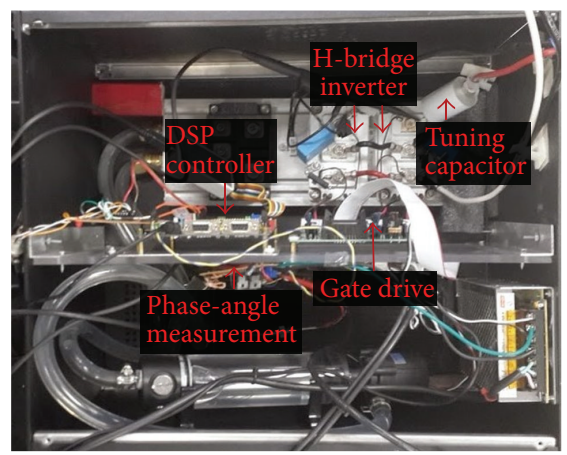

(b)

Figure 7: (a) Three-axis platform; (b) power inverter and frequency control electronics.

purposes. The 3-axis platform shown in Figure 7(a) is modified from a CNC machine (Model DHC, PlasmaCAM, Inc., Colorado City, CO, USA). The platform has a width of $1.75 \mathrm{~m}$, a height of $1.65 \mathrm{~m}$, and a depth of $1.65 \mathrm{~m}$ with a maximum speed of $25 \mathrm{~m} / \mathrm{min}$ in the horizontal direction and $2 \mathrm{~m} / \mathrm{min}$ in the vertical direction. The movable ranges are $1.2 \mathrm{~m} \times 1.2 \mathrm{~m}$ in the horizontal plane and $0.6 \mathrm{~m}$ in the vertical direction. Figure 7(b) is the power inverter of the wireless charging and was used to drive the coil and generate a magnetic field for alignment. The user operated the control panel to adjust the coil alignment based on the computer interface's navigational information. The distance between the two coils was recorded after the user completed the test. The users did not have access to visually obtain the two coils' spatial distribution to ensure the functionality of the alignment system.

\subsection{Experimental Results with Lateral Distance Detection.} Figure 8 shows the experimental comparison between measured values by the charging electronics and the true values. Figure $8(\mathrm{a})$ is the experimental result when the coil air gap is $12 \mathrm{~cm}$ and Figure 8(b) is the result when the gap is $11.5 \mathrm{~cm}$. The mean error is $0.2 \mathrm{~cm}$ in Figure 8 (a) while it is $0.34 \mathrm{~cm}$ in Figure 8(b). As the system was calibrated at an air gap of $12 \mathrm{~cm}$, the system shows more accurate measurement at $12 \mathrm{~cm}$ than $11.5 \mathrm{~cm}$. The measurement error is relatively higher when the two coils are very close together $(<2 \mathrm{~cm})$. This is because that magnetic coupling is similar when the two coils are almost strictly aligned. In this case, the resonant frequency of the WPT system varies little, making the system have relatively low sensitivity when the charging coils are in close to perfect alignment. Since the wireless charging system can endure some misalignment, the alignment can still meet the requirements as long as the navigation error is lower than $10 \mathrm{~cm}$ for a common wireless EV charger.

Figure 9(a) shows the measurement accuracy of the alignment system when the lateral distance between two coils is $5 \mathrm{~cm}, 10.5 \mathrm{~cm}$, and $15 \mathrm{~cm}$. The measurement was repeated 10 times for each lateral distance. The mean error is $0.2 \mathrm{~cm}$ $(\mathrm{STD}=0)$ at the misalignment of $5 \mathrm{~cm}, 0.25(\mathrm{STD}=0.05)$ at $10.5 \mathrm{~cm}$, and $0.12 \mathrm{~cm}($ STD $=0.03)$ at $15 \mathrm{~cm}$. These data show that the system has a high measurement repeatability.

5.3. Minor Adjustment with Auxiliary Coils. Figure 9(b) shows the positioning accuracy between the two well aligned charging coils with assistance from the four auxiliary coils. The experiment was repeated three times for each starting 


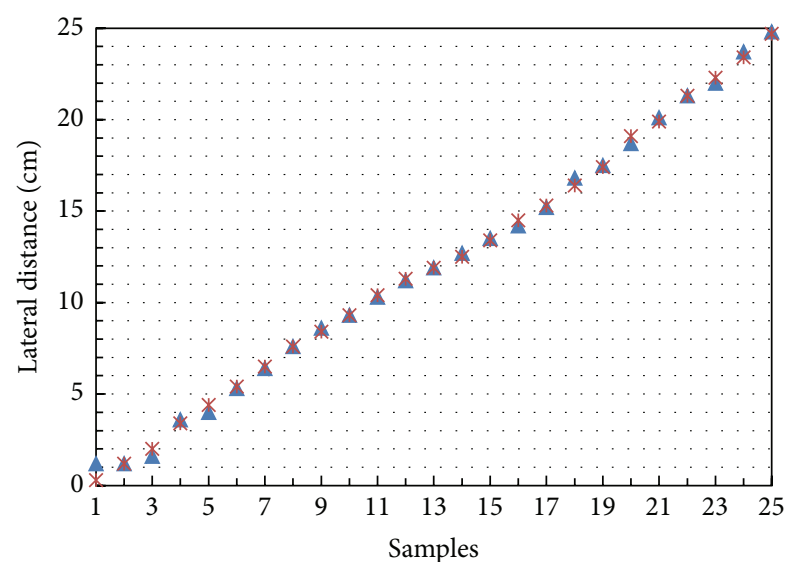

$\Delta$ Measured value $*$ True value

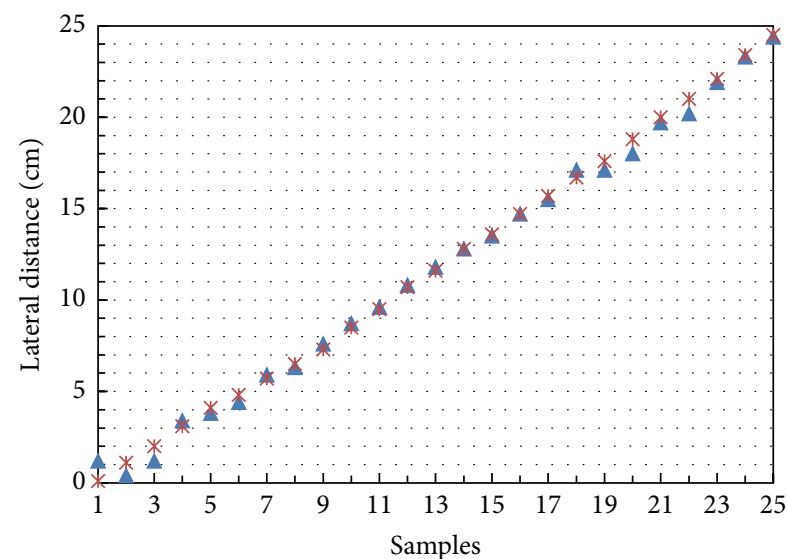

A Measured value * True value

(a)

(b)

FIGURE 8: Experimental comparison between measured and true values across the whole measurement range. (a) Height = $12 \mathrm{~cm}$; (b) height $=11.5 \mathrm{~cm}$.

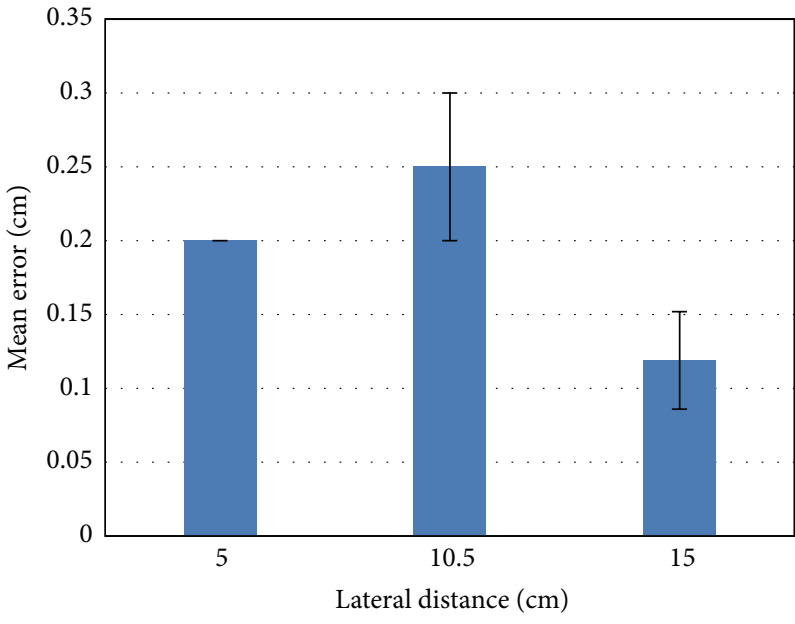

(a)

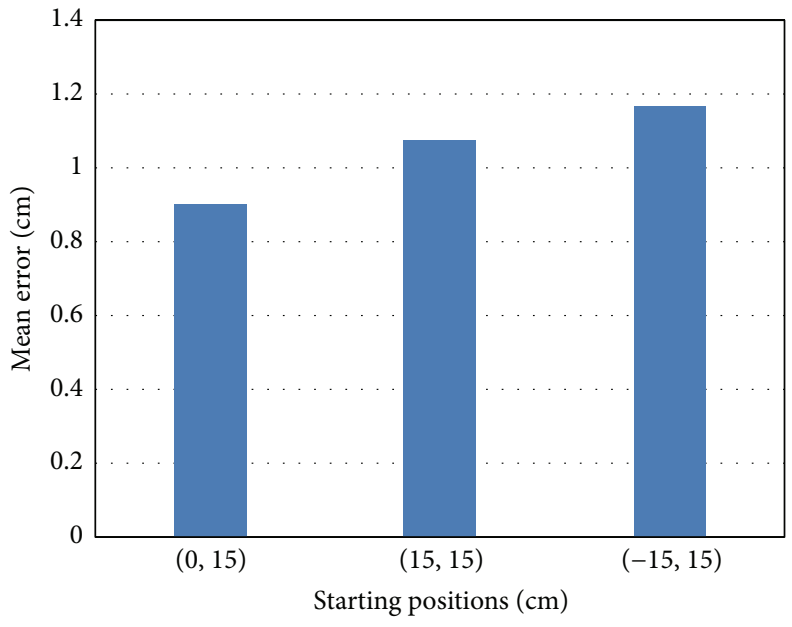

(b)

FiguRE 9: (a) Measurement accuracy at three lateral distances under a chassis height of $11.5 \mathrm{~cm}$; (b) measurement accuracy between two well aligned coils under a chassis height of $11.5 \mathrm{~cm}$. The measurement was repeated 3 times for each starting position.

position. The mean error is $0.9 \mathrm{~cm}$ when the starting point's coordinate is $(0,15), 1.1 \mathrm{~cm}$ for $(15,15)$, and $1.2 \mathrm{~cm}$ for $(-15$, $15)$. Since the $(0,15)$ starting point is located on the $y$-axis, the error is slightly smaller than the other two conditions whose starting positions are in the first and second quadrants, respectively. All three mean errors are lower than $1.2 \mathrm{~cm}$, which is within the acceptable range of misalignment in wireless EV charging.

5.4. Comparison with Other Alignment Solutions. Table 2 shows the performance comparison of different alignment technologies used in EVWC. All the techniques listed in Table 2 can achieve accuracies of several centimeters. The magnetic alignment solution is of low cost as it shares the same hardware and software with the wireless charging system. Since the magnetic field can be shaped by the existence of an EV, the effective detection distance of magnetic alignment might be limited. The machine vision can be a direct way to navigate the EV drivers to park. One drawback of machine vision is that it can be out of function in a snow day due to the fact that the charging stations are always buried underground. Ultrasonic and RF positioning is a mature technique and has wide application in indoor navigation. As RF positioning requires radio readers and tags, it might be high in cost for wireless chargers. Ultrasonic positioning might not work when debris is placed on ground and hinders ultrasound transmission. 
TABLE 2: Comparison among potential alignment techniques for wireless EV chargers.

\begin{tabular}{llll}
\hline Techniques & Description & Pros & Cons \\
\hline $\begin{array}{l}\text { Magnetic } \\
\text { sensing }\end{array}$ & $\begin{array}{l}\text { Using existing coils and } \\
\text { auxiliary coils }\end{array}$ & $\begin{array}{l}\text { Simple and low-cost } \\
\text { implementation by sharing } \\
\text { the charging facility }\end{array}$ & $\begin{array}{l}\text { Detection distance } \\
\text { might be relatively small }\end{array}$ \\
\hline Machine vision & $\begin{array}{l}\text { Including a camera and } \\
\text { monitor }\end{array}$ & $\begin{array}{l}\text { Visibly detect the charging } \\
\text { station }\end{array}$ & $\begin{array}{l}\text { Invalid when ground is } \\
\text { covered with snow }\end{array}$ \\
\hline $\begin{array}{l}\text { Ultrasonic } \\
\text { positioning }\end{array}$ & $\begin{array}{l}\text { Including a few ultrasonic } \\
\text { transmitters and receivers }\end{array}$ & $\begin{array}{l}\text { Mature technology and can } \\
\text { be high in accuracy }\end{array}$ & $\begin{array}{l}\text { High cost and difficulty } \\
\text { to go through debris }\end{array}$ \\
\hline RF positioning & $\begin{array}{l}\text { Including radio readers and } \\
\text { multiple tags }\end{array}$ & $\begin{array}{l}\text { Mature technology and } \\
\text { simple implementation }\end{array}$ & $\begin{array}{l}\text { High cost and } \\
\text { complexity }\end{array}$ \\
\hline
\end{tabular}

\section{Conclusion}

A magnetic alignment system using existing charging electronics demonstrates that it can be a practical approach to address the misalignment issues in wireless EV charging. The distance between the two coils is transmitted to the user immediately for navigation purposes. The four auxiliary coils provide direction information and help the driver adjust the vehicle to ensure good alignment. The positioning error of the magnetic alignment system is within $1.2 \mathrm{~cm}$ and allows for highly efficient wireless charging. The whole system is based on the existing wireless charging facility except for the four small auxiliary coils; thus, the overall cost of the system should be much smaller than an additional alignment system such as RF positioning.

\section{Conflict of Interests}

The authors declare that there is no conflict of interests regarding the publication of this paper.

\section{Acknowledgments}

This work was funded by the Georgia Research for Academic Partnership in Engineering Award from Southern Company Services, Inc. and the Campus Sustainability Grant from the University of Georgia Office of Sustainability.

\section{References}

[1] G. A. Covic and J. T. Boys, "Modern trends in inductive power transfer for transportation applications," IEEE Journal of Emerging and Selected Topics in Power Electronics, vol. 1, no. 1, pp. 28-41, 2013.

[2] J. Deng, W. Li, T.-D. Nguyen, S. Li, and C. Mi, "Compact and efficient bipolar pads for wireless power chargers: design and analysis," IEEE Transactions on Power Electronics, vol. 20, pp. 6130-6140, 2015.

[3] C. Duan, C. Jiang, A. Taylor, and K. H. Bai, "Design of a zero-voltage-switching large-air-gap wireless charger with low electric stress for electric vehicles," IET Power Electronics, vol. 6, no. 9, pp. 1742-1750, 2013.

[4] T. M. Fisher, K. B. Farley, Y. Gao, H. Bai, and Z. T. Tse, "Electric vehicle wireless charging technology: a state-of-the-art review of magnetic coupling systems," Wireless Power Transfer, vol. 1, no. 2, pp. 87-96, 2014.

[5] Y. Gao, K. B. Farley, A. Ginart, and Z. T. H. Tse, "Safety and efficiency of the wireless charging of electric vehicles," Proceedings of the Institution of Mechanical Engineers D: Journal of Automobile Engineering, 2015.

[6] Y. Gao, K. B. Farley, and Z. T. H. Tse, "Investigating safety issues related to electric vehicle wireless charging technology," in Proceedings of the IEEE Transportation Electrification Conference and Expo (ITEC '14), pp. 1-4, Dearborn, Mich, USA, June 2014.

[7] C. Duan, C. Jiang, A. Taylor, and K. Bai, "Design of a zerovoltage-switching large-air-gap wireless charger with low electrical stress for Plugin Hybrid Electric Vehicles," in Proceedings of the IEEE Transportation Electrification Conference and Expo (ITEC '13), pp. 1-5, IEEE, June 2013.

[8] J. M. Miller and A. Daga, "Elements of wireless power transfer essential to high power charging of heavy duty vehicles," IEEE Transactions on Transportation Electrification, vol. 1, no. 1, pp. 26-39, 2015.

[9] Y. Gao, K. B. Farley, and Z. T. H. Tse, "A uniform voltage gain control for alignment robustness in wireless EV charging," Energies, vol. 8, no. 8, pp. 8355-8370, 2015.

[10] S. A. Birrell, D. Wilson, C. P. Yang, G. Dhadyalla, and P. Jennings, "How driver behaviour and parking alignment affects inductive charging systems for electric vehicles," Transportation Research Part C: Emerging Technologies, vol. 58, pp. 721-731, 2015.

[11] J. Schneider, SAE J2954 Overview and Path Forward, SAE International, Warrendale, Pa, USA, 2013.

[12] A. Ravisankar, A. Agarwal, A. Kulkarni et al., "A GPS-less navigation system," in Proceedings of the 1st Texas Instruments India Educators' Conference (TIIEC '13), pp. 290-294, IEEE, Bangalore, India, April 2013.

[13] W. Ni, I. Collings, X. Wang et al., "Radio alignment for inductive charging of electric vehicles," IEEE Transactions on Industrial Informatics, vol. 11, pp. 427-440, 2015.

[14] C. Shuwei, L. Chenglin, and W. Lifang, "Research on positioning technique of wireless power transfer system for electric vehicles," in Proceedings of the IEEE Conference and Expo Transportation Electrification Asia-Pacific (ITEC Asia-Pacific '14), pp. 1-4, Beijing, China, August 2014.

[15] Wireless Electric Vehicle Charging-Plugless Power by Evatran Group, Inc, https://www.pluglesspower.com/.

[16] H. H. Wu, H. Malek, and M. P. Masquelier, "Determining physical alignment between magnetic couplers for wireless power transfer," US Patent 20,150,155,095, 2015. 
[17] G. J. Ho, S. K. Dong, J. Y. Pal, and K. Jaihie, "Parking slot markings recognition for automatic parking assist system," in Proceedings of the IEEE Intelligent Vehicles Symposium (IV '06), pp. 106-113, IEEE, June 2006.

[18] C. Medina, J. C. Segura, and Á. De la Torre, "Ultrasound indoor positioning system based on a low-power wireless sensor network providing sub-centimeter accuracy," Sensors, vol. 13, no. 3, pp. 3501-3526, 2013. 


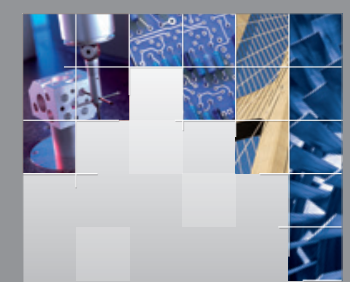

\section{Enfincering}
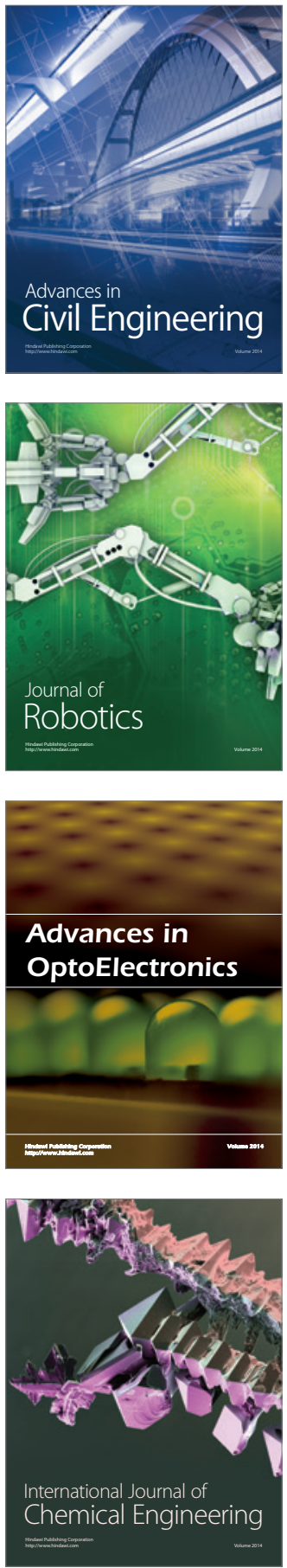

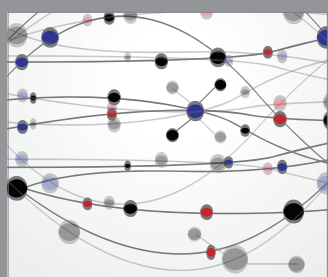

The Scientific World Journal

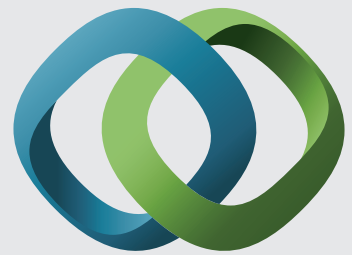

\section{Hindawi}

Submit your manuscripts at

http://www.hindawi.com
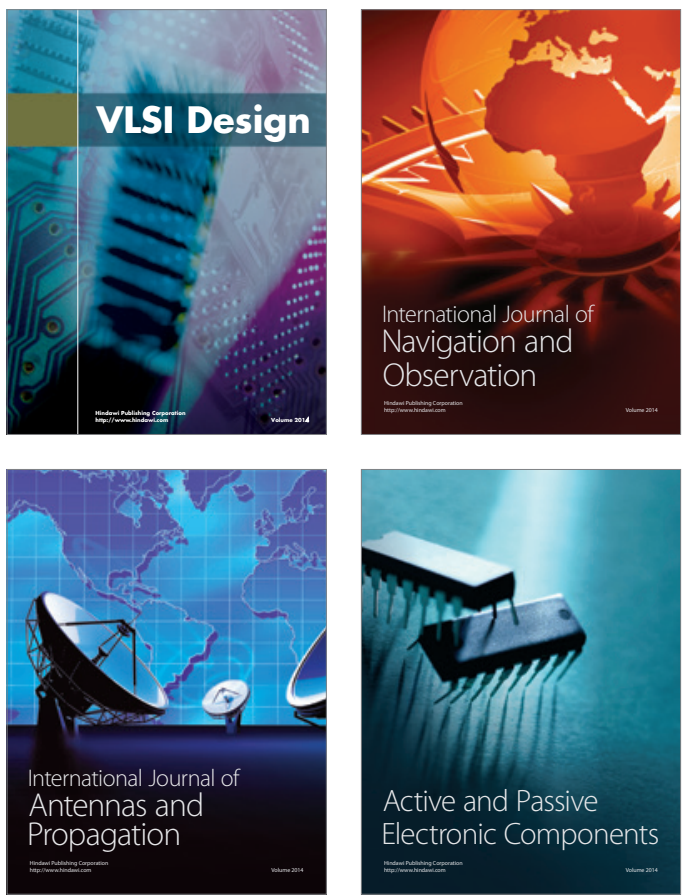
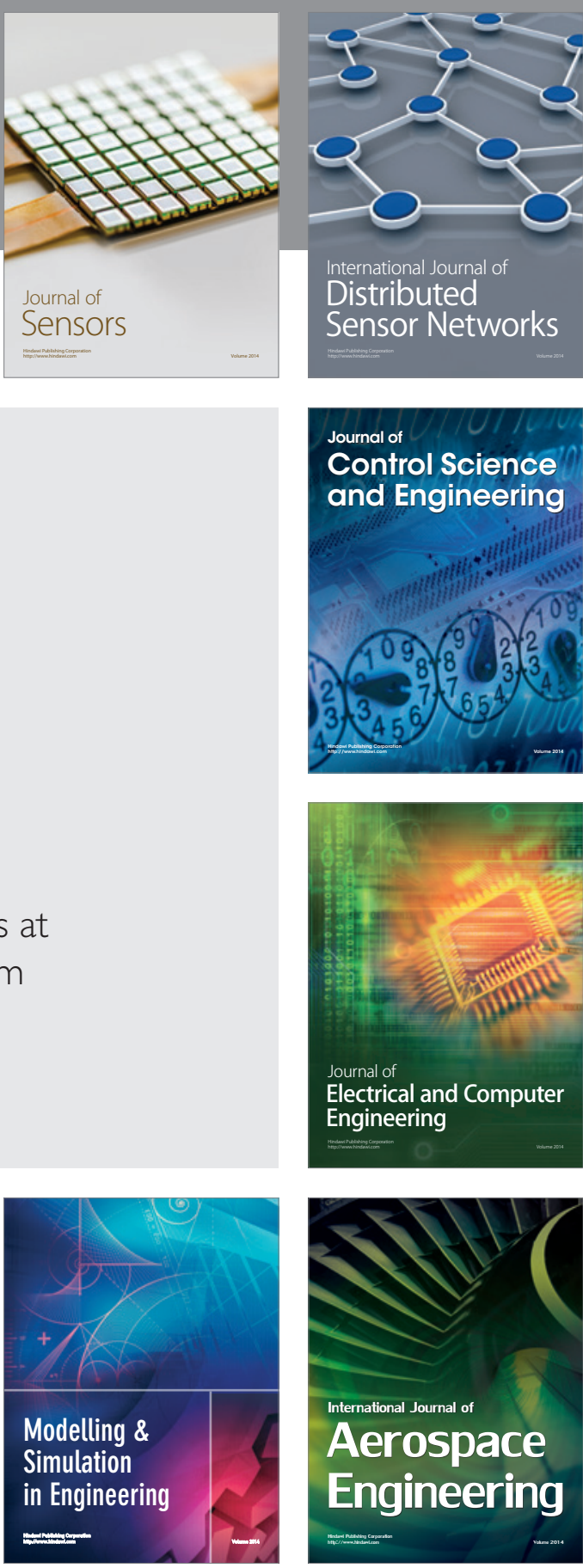

International Journal of

Distributed

Sensor Networks

Journal of

Control Science

and Engineering
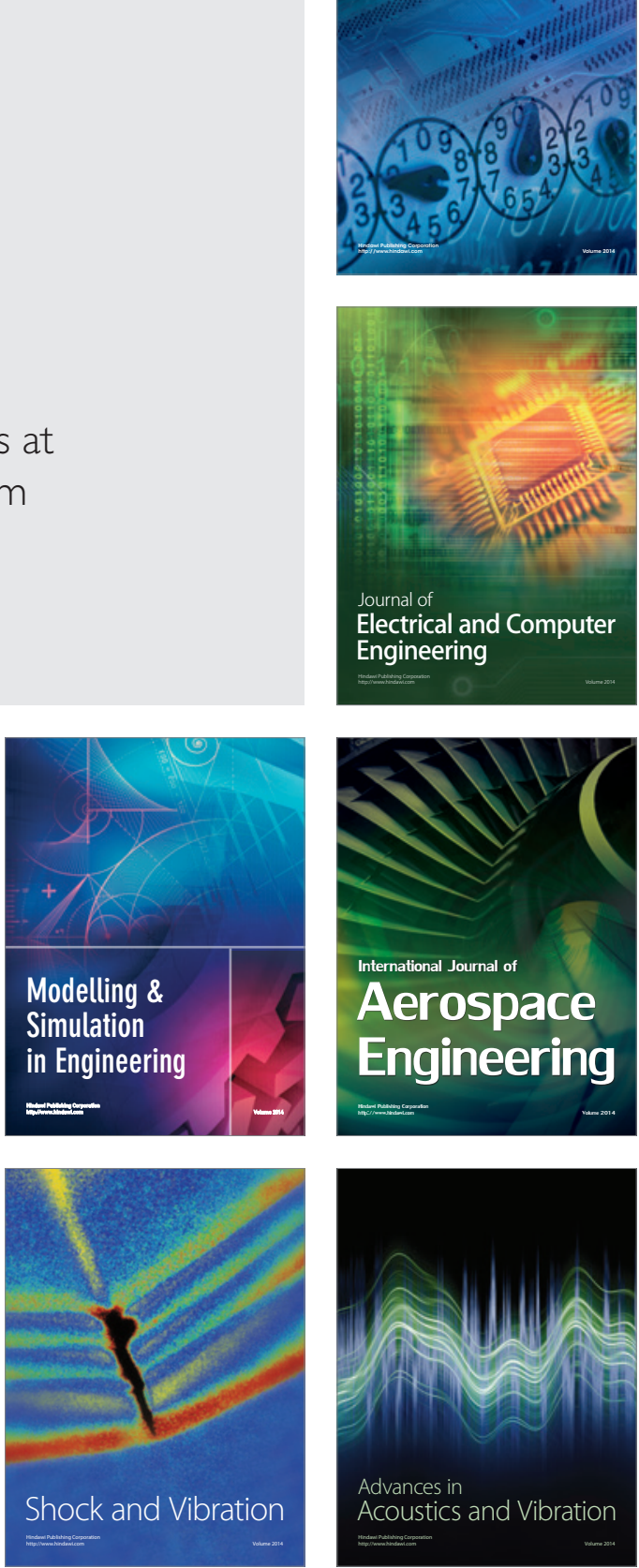